\title{
Altered regional gray matter volume in Chinese female patients with bulimia nervosa
}

\author{
Xiao Li ${ }^{1}$, Xiaowei Liu', Yu Wang ${ }^{1}$, Lingfei Li', Linli Zheng ${ }^{1}$, Yaya Liư ${ }^{1,2}$, Jing Ma and Lan Zhang ${ }^{1 *}$
}

\begin{abstract}
Background: Bulimia nervosa (BN) is a psychiatric disorder with unclear pathophysiology. Several studies have associated BN with structural and functional changes in the brain, but findings have been inconsistent. Here we explored this potential association in a small group of Chinese women with BN.

Methods: This retrospective study examined 34 women with BN and 34 age-matched healthy controls, all of whom underwent T1-weighted magnetic resonance imaging (MRI). Voxel-based morphometry was carried out to explore alterations in regional grey matter volume (GMV) that may be associated with BN.

Results: The BN group showed smaller GMV in the left medial superior frontal gyrus (SFGmed.L), right superior temporal gyrus (STG.R), right median cingulate and paracingulate gyri (DCG.R), left median cingulate and paracingulate gyri (DCG.L) and left dorsolateral superior frontal gyrus (SFGdor.L). No regions showing GMV increases in BN were identified. The GMV reduction did not correlate with body mass index, duration of illness, or patients' self-esteem or overall self-evaluation. GMV reduction correlated negatively with age in the SFGmed. L $(r=-0.516, P<0.005)$, DCG. $R(r=-0.556, P<0.005), D C G$. L $(r=-0.576, P<0.05)$ and SFGdor. $L(r=-0.576, P<0.005)$.

Conclusions: Women with BN show reduced GMV in several brain regions, but it is difficult to know whether these changes are the result of BN pathology or of binge-eating and compensatory behavior. These changes may be associated with impaired inhibitory control, body dissatisfaction and emotion dysregulation.
\end{abstract}

Keywords: Bulimia nervosa, MRl, Grey matter volume, Voxel-based morphometry

\section{Background}

Bulimia nervosa $(\mathrm{BN})$ is an eating disorder characterized by recurrent episodes of binge eating and inappropriate compensatory behaviors to prevent weight gain [1]. It usually occurs in young females and can lead to severe medical complications affecting all body systems $[2,3]$. The neurobiological processes underlying $\mathrm{BN}$ are unclear. Several studies have provided evidence that BN and other eating disorders are associated with structural and functional changes in brain regions, as detected using magnetic resonance imaging (MRI) (Table 1). For example, studies based on voxel-based morphometry (VBM) from MRI images have associated $\mathrm{BN}$ with increased grey matter

\footnotetext{
* Correspondence: huaxizhanglan@126.com

${ }^{1}$ Mental Health Center, West China Hospital, Sichuan University, No. 28 Dian

Xin Nan Road, Chengdu 610041, Sichuan, China

Full list of author information is available at the end of the article
}

volume (GMV) in the medial orbitalfrontal cortex and the ventral striatum [4], as well as in the insula [5], lingual gyri and inferior parietal lobule [6]. These and other studies also found reduced GMV in caudate and putamen $[5,7]$, bilateral medial frontal, precentral gyri, right postcentral gyrus, left superior (SFG) and inferior frontal gyri [6]. Some brain structural studies have found cortical abnormalities in $\mathrm{BN}$, such as reduced cortical thickness in the bilateral frontal, temporal and parietal lobes, negtively related to the severity of $\mathrm{BN}$ symptoms [8]; and reduced cortical thickness in the right pars triangularis, right superior parietal and left dorsal posterior cingulate cortices as well as greater cortical thickness in the left ventral posterior cingulate cortex [9]. These and other brain structural studies have found abnormal structural connectivity in BN. Greater structural connectivity has been found among the insula, orbitofrontal cortex and ventral striatum, as

(C) The Author(s). 2020 Open Access This article is distributed under the terms of the Creative Commons Attribution 4.0 International License (http://creativecommons.org/licenses/by/4.0/), which permits unrestricted use, distribution, and 
Table 1 A review table of the existing structural work in bulimia nervosa

\begin{tabular}{|c|c|c|c|c|c|}
\hline \multirow[t]{2}{*}{ Authors\&Journal } & \multirow[t]{2}{*}{ Participants } & \multirow{2}{*}{$\begin{array}{l}\text { Mean Age } \\
\text { (SD) }\end{array}$} & \multirow[t]{2}{*}{ Method } & \multicolumn{2}{|l|}{ Findings } \\
\hline & & & & Regional Differences & $\begin{array}{l}\text { Total Volume } \\
\text { Difference }\end{array}$ \\
\hline $\begin{array}{l}\text { Schäfer et.al } \\
\text { (2010) [4] Neuroimage. 2010;50 } \\
\text { (2):639-43 }\end{array}$ & $\begin{array}{l}\operatorname{BN}(n=14) \\
\operatorname{BED}(n=17) \\
\mathrm{HC}(n=19)\end{array}$ & $\begin{array}{l}\text { BN:23.1 (3.8) } \\
\text { BED:26.4 } \\
(6.4) H C: 22.3 \\
(2.6)\end{array}$ & VBM & $\begin{array}{l}\text { Increased GMV of the medial OFC } \\
\text { and the ventral striatum in } B N \\
(B N>H C) \text {. }\end{array}$ & Not assessed \\
\hline $\begin{array}{l}\text { Frank et.al(2013) [5] } \\
\text { Am J Psychiatry. 2013;170 } \\
\text { (10):1152-60 }\end{array}$ & $\begin{array}{l}\text { AN(n=19) } \\
\text { Recovered } \\
\text { AN(n=24) } \\
\text { BN }(n=20) \\
\mathrm{HC}(n=24)\end{array}$ & $\begin{array}{l}\text { AN:23.1 (5.8) } \\
\text { Recovered } \\
\text { AN:30.3 (8.1) } \\
\text { BN:25.2 (5.3) } \\
\text { HC:27.4 (6.3) }\end{array}$ & VBM & $\begin{array}{l}\text { Increased GMV in the Left } \\
\text { orbitofrontal cortex and anterior } \\
\text { ventral insula (BN }>\mathrm{HC} \text { );reduced } \\
\text { GMV in the bilateral dorsal } \\
\text { caudate and dorsal putamen in } \\
\text { BN (BN }<\mathrm{HC} \text { ). }\end{array}$ & $\begin{array}{l}\text { There was no } \\
\text { significant } \\
\text { difference } \\
\text { between BN and } \\
\mathrm{HC} \text { in GMV, WMV } \\
\text { and } \operatorname{TIV}(P>0.05) \text {. }\end{array}$ \\
\hline $\begin{array}{l}\text { Coutinho et.al(2015) [7] Int J } \\
\text { Eat Disord. 2015;48 (2):206-14 }\end{array}$ & $\begin{array}{l}\mathrm{BN}(n=21) \mathrm{HC} \\
(\mathrm{n}=20)\end{array}$ & $\begin{array}{l}\mathrm{BN}: 31.57 \\
(8.27) \mathrm{HC}: \\
30.90(8.79)\end{array}$ & VBM & $\begin{array}{l}\text { Reduced volume of caudate } \\
\text { nucleus in } \mathrm{BN}(\mathrm{BN}<\mathrm{HC})\end{array}$ & $\begin{array}{l}\text { There was no } \\
\text { significant } \\
\text { difference } \\
\text { between } B N \text { and } \\
\text { HC in TIV }(P>0.05) \text {. }\end{array}$ \\
\hline In this research & $\begin{array}{l}\mathrm{BN}(\mathrm{n}=34) \mathrm{HC} \\
(\mathrm{n}=34)\end{array}$ & $\begin{array}{l}\mathrm{BN}: 22.85 \\
(3.89) \mathrm{HC}: \\
22.26(2.53)\end{array}$ & VBM & $\begin{array}{l}\text { Reduced GMV in the SFGmed. } L \text {, } \\
\text { STG. R, DCG. R, DCG. } L \text { and } \\
\text { SFGdor. } L(B N<H C) \text {. }\end{array}$ & $\begin{array}{l}\text { There were no } \\
\text { significant } \\
\text { differences } \\
\text { between patients } \\
\text { and controls in } \\
\text { total GMV, WMV } \\
\text { or TIV(P }>0.05) \text {. }\end{array}$ \\
\hline $\begin{array}{l}\text { Marsh et.al(2015) [6] Biol } \\
\text { Psychiatry. 2015;77 (7):616-23 }\end{array}$ & $\begin{array}{l}\mathrm{BN}(\mathrm{n}=34) \mathrm{HC} \\
(\mathrm{n}=34)\end{array}$ & $\begin{array}{l}\mathrm{BN}: 21.6(6.0) \\
\mathrm{HC}: 22.08 \\
(6.5)\end{array}$ & $\begin{array}{l}\text { Morphological } \\
\text { analysis } \\
\text { including VBM } \\
\text { and Cortical } \\
\text { Thickness }\end{array}$ & $\begin{array}{l}\text { Increased GMV in lingual gyri and } \\
\text { inferior parietal lobule in } \mathrm{BN} \\
(\mathrm{BN}>\mathrm{HC} \text { ); reduced GMV in } \\
\text { bilateral medial frontal and } \\
\text { precentral gyri, left superior and } \\
\text { inferior frontal gyri, the right } \\
\text { postcentral gyrus and bilateral } \\
\text { temporoparietal areas (BN }<\mathrm{HC} \text { ). }\end{array}$ & $\begin{array}{l}\text { The TIV did not } \\
\text { differ across the } \\
\text { BN and control } \\
\text { group }(P>0.05) \text {. }\end{array}$ \\
\hline $\begin{array}{l}\text { Frank et.al(2016) [10] Transl } \\
\text { Psychiatry. 2016;6 (11):e932 }\end{array}$ & $\begin{array}{l}\mathrm{AN}(n=26) \mathrm{BN}(n=25) \mathrm{HC} \\
(\mathrm{n}=26)\end{array}$ & $\begin{array}{l}\text { AN:23.23 } \\
\text { (5.26) BN: } \\
24.64(4.22) \\
\text { HC:24.39 } \\
(3.49)\end{array}$ & $\begin{array}{l}\text { Structural and } \\
\text { effective } \\
\text { connectivity }\end{array}$ & $\begin{array}{l}\text { Greater structural connectivity in } \\
\text { insula, orbitofrontal cortex and } \\
\text { ventral striatum (BN }>\mathrm{HC}) \text {, but } \\
\text { lower connectivity in } \\
\text { orbitofrontal cortex, amygdala } \\
\text { and hypothalamus in } \mathrm{BN}(\mathrm{BN}< \\
\mathrm{HC}) \text {. }\end{array}$ & Not assessed \\
\hline $\begin{array}{l}\text { Berner et al.(2018) [9] } \\
\text { J Psychiatry Neurosci. 2018;43 } \\
\text { (3):151-160 }\end{array}$ & $\mathrm{BN}(n=28) \mathrm{HC}(n=21)$ & $\begin{array}{l}\mathrm{BN}: 18.8(4.1) \\
\mathrm{HC}: 19.2(5.5)\end{array}$ & $\begin{array}{l}\text { Cortical } \\
\text { thickness }\end{array}$ & $\begin{array}{l}\text { Greater cortical thickness in the } \\
\text { left ventral posterior cingulate } \\
\text { cortex in } \mathrm{BN}(\mathrm{BN}>\mathrm{HC}) \text {; reduced } \\
\text { thickness of the right pars } \\
\text { triangularis, right superior parietal } \\
\text { and left dorsal posterior cingulate } \\
\text { cortices }(\mathrm{BN}<\mathrm{HC} \text { ). }\end{array}$ & Not assessed \\
\hline $\begin{array}{l}\text { Westwater et.al(2018) [8] Psychiatry Res Neuroimaging. } \\
\text { 2018;271:118-125 }\end{array}$ & $\mathrm{BN}(n=37)$ & $\mathrm{BN}: 22.6(4.1)$ & $\begin{array}{l}\text { Cortical } \\
\text { thickness and } \\
\text { structural } \\
\text { connectivity }\end{array}$ & $\begin{array}{l}\text { The cortical thickness in the left } \\
\text { middle frontal gyrus, right } \\
\text { superior frontal gyrus and } \\
\text { bilateral orbitofrontal cortex } \\
\text { (OFC) and temporoparietal } \\
\text { regions negtively related to the } \\
\text { severity of BN symptoms. The } \\
\text { structural connectivity in the left } \\
\text { OFC and middle temporal cortex } \\
\text { negtively related to the severity } \\
\text { of symptoms, while in the right } \\
\text { superior parietal lobule positively } \\
\text { related to the severity of } \\
\text { symptoms. }\end{array}$ & Not assessed \\
\hline
\end{tabular}

well as among the bilateral frontal, temporal and parietal lobes. Conversely, lower connectivity has been found in the orbitofrontal cortex, amygdala and hypothalamus $[9,10]$.

These various studies have given inconsistent findings, likely reflecting small samples, differences in patient populations, and differences in methodology. For example, some studies corrected for age and total intracranial volume (TIV), while others corrected for age and body mass index (BMI). Several studies did not consider potential effects of medication. Many studies have not examined whether structural changes in the brain 
correlate with low self-esteem and self-evaluation, which are core features of BN and other eating disorders $[11,12]$.

The present study aimed to help clarify the potential association of BN with altered GMV in the brain, and to examine whether these structural changes correlate with patient's self-evaluation. We retrospectively examined a small population of Chinese women with $\mathrm{BN}$ at our medical center, comparing them to a matched group of healthy controls.

\section{Methods}

\section{Participants}

This retrospective study involved 34 women diagnosed with BN at the Mental Health Center of West China Hospital, Sichuan University. The patients had engaged in binge eating and compensatory behaviors at least once a week during the three months prior to enrollment in the study. As controls, we recruited 34 agematched women with BMI within the normal range of 18.5-23.9 who reported no history of eating disorders or other psychiatric disorders. Controls were recruited from the community through public advertisements. This study was approved by the Ethics Committee of West China Hospital, and all subjects provided written informed consent.

Patients and controls were assessed by two psychiatrists using the structured clinical interview for DSM-V disorders (SCID). All study subjects were right-handed, and none was currently taking medications or reported a history of major psychiatric disorders, head trauma, substance abuse or dependence, or neurologic disease. None of the subjects reported having metal implants or a pacemaker. Nine BN patients had mild anxiety and depressive symptoms based on the SCID, but we did not exclude them because these symptoms occur often in $\mathrm{BN}[13,14]$.

\section{Clinical psychological assessment of patients}

All patients completed the revised Chinese version of the Core Self-Evaluation Scale (CSES) and the Chinese version of the Rosenberg Self-Esteem Scale (RSES). The revised Chinese CSES uses 10 items to assess core selfevaluation, and it shows acceptable reliability and validity $[13,15]$. The survey applies a 5-point scoring method, and the total score ranges from 10 to 50 points. The national norm on the CSES is $36.05 \pm 5.21$ for Chinese undergraduate women [15], and CSES scores of our patients were compared to this norm.

The RSES assesses self-esteem [16] and includes 10 items, with items 3, 5, 8, 9, 10 negatively worded. Each item is scored on a 4-point scale, and the individual item scores are summed to obtain a total score. We compared the RSES scores of our patients to the mean RSES score of $28.73 \pm 4.48$ reported for undergraduates in Beijing [17]. This norm did not vary significantly with gender in that study.

\section{MRI data acquisition}

MR images were obtained using a Philips $3.0 \mathrm{~T}$ system. All subjects underwent 3D T1-weighted volumetric scanning with the following parameters: orientation, sagittal; matrix size, $256 \times 256$; field of view (FOV), $256 \times$ $256 \mathrm{~mm}$; slice thickness, $1 \mathrm{~mm}$; gap, none; flip angle, $7^{\circ}$; repetition time (TR), $8.2 \mathrm{~ms}$; echo time (TE), $3.8 \mathrm{~ms}$; voxel size, $1 \times 1 \times 1 \mathrm{~mm}$. During MRI, all subjects were asked to relax, keep their eyes closed without falling sleep and their head as motionless as possible, and not to think of anything in particular.

\section{VBM}

MRI data were analyzed using SPM8 (Wellcome Trust Centre for Neuroimaging, Institute of Neurology, London, UK) and the VBM toolbox VBM8 (www.neuro. uni-jena.de/vbm/), both run within Matlab R2013b. Structural images were normalized to Montreal Neurological Institute (MNI) standard space and segmented into grey matter (GM), white matter (WM) and cerebrospinal fluid (CSF) using the unified segmentation approach. Finally, grey matter images were smoothed using an 8-mm full-width half-maximum Gaussian kernel.

\section{Statistical analysis}

GMV in different brain regions was compared between patients and controls using the two-samples $t$ test in SPM8. Covariates were age and TIV, defined as the sum of GM, WM and CSF volumes. Multiple comparisons were corrected using the family-wise error approach at a cluster level, with a corrected threshold of $P<0.001$. An absolute threshold was set at 0.2 in all computations.

The two-samples $t$ test in SPSS 20.0 (IBM, Chicago, IL, USA) was used to compare patients and controls in terms of clinico-demographic data as well as total GM, WM, CSF and intracranial volumes. Regions of interest (ROIs) showing GMV changes were defined using the "region of interest extraction" tool in xjView (www.alivelearn.net/ xjview8/) via the SPM toolbox. Pearson correlation analysis was conducted within SPSS to explore relationships between ROIs and clinical variables after Bonferroni correction, with significance defined as $P<0.01$.

\section{Results}

3Clinico-demographics characteristics of participants

Table 2 summarizes the demographics and clinical characteristics of patients and healthy controls. The groups did not differ significantly in age, BMI or years of education $(P>0.05)$. Patients showed lower mean RSES and 
Table 2 Demographic variables,clinical characteristics and whole brain tissue volumes of the subjects

\begin{tabular}{|c|c|c|c|}
\hline Characteristic & BN $(N=34)$ Mean \pm SD & $\mathrm{HC}(N=34)$ Mean $\pm S D$ & $P$ \\
\hline Age & $22.85 \pm 3.89$ & $22.26 \pm 2.53$ & NS \\
\hline BMI $\left(\mathrm{kg} / \mathrm{m}^{2}\right)$ & $20.46 \pm 2.80$ & $20.52 \pm 1.52$ & NS \\
\hline Duration of illness (years) ${ }^{a}$ & $2.92 \pm 2.35$ & - & - \\
\hline Education (years) & $15.53 \pm 2.43$ & $16.09 \pm 2.45$ & NS \\
\hline CSES global score ${ }^{a}$ & $33.24 \pm 3.56$ & - & \\
\hline RSES global score ${ }^{a}$ & $25.76 \pm 5.47$ & - & \\
\hline \multicolumn{4}{|l|}{ Whole brain tissue volumes (VBM) } \\
\hline Grey matter volume (ml) & $660.56 \pm 34.17$ & $662.97 \pm 37.11$ & NS \\
\hline White matter volume (ml) & $525.68 \pm 39.46$ & $526.02 \pm 48.38$ & NS \\
\hline CSF volume (ml) & $227.69 \pm 22.82$ & $212.68 \pm 24.09$ & $<0.05$ \\
\hline Total intracranial volume (ml) & $1413.94 \pm 78.41$ & $1401.67 \pm 91.04$ & NS \\
\hline
\end{tabular}

NS not significant, $B M I$ body mass index;

CSES the Core Self-Evaluation Scale, RSES the Rosenberg Self-Esteem Scale

at the time of scaning

CSES scores than the corresponding norms from healthy populations (see Methods).

\section{VBM}

\section{Whole brain tissue volumes}

There were no significant differences between patients and controls in total GMV, WMV or TIV ( $\mathrm{P}>0.05$, Table 2). In contrast, patients showed a larger total CSF volume.

\section{Regional GMV}

Using age and TIV as confounding covariates in VBM analysis, we identified five clusters of regional GMV after correction for multiple comparisons at the cluster level (threshold $P<0.001$ ). Patients showed lower GMV in the left medial superior frontal gyrus (SFGmed.L), right superior temporal gyrus (STG.R), right median cingulate and paracingulate gyri (DCG.R), left median cingulate and paracingulate gyri (DCG.L) and left dorsolateral superior frontal gyrus (SFGdor.L) (Table 3 and Figs. 1 and 2). In none of the regions did patients show increased GMV.

Correlations of GMV reduction with patient characteristics BN-associated GMV reductions did not vary significantly with BMI, duration of illness, or total scores on the RSES or CSES $(P>0.05)$. In contrast, age did correlate negatively with GMV in the SFGmed. $\mathrm{L}(\mathrm{r}=-0.516, P<0.005)$, DCG. $\mathrm{R}$ $(\mathrm{r}=-0.556, \mathrm{P}<0.005)$, DCG. $\mathrm{L}(\mathrm{r}=-0.576, P<0.05)$ and SFGdor. $\mathrm{L}(\mathrm{r}=-0.576, \mathrm{P}<0.005)$ (See Fig. 3).

\section{Discussion}

\section{Global brain volume alterations}

We found no significant differences between $\mathrm{BN}$ patients or controls in total GMV, WMV or intracranial volume, which is consistent with some previous studies in female patients $[18,19]$. Our patients did show increased CSF volume, consistent with results obtained with one group

Table 3 Regional GMV changes in patients with BN compared to healthy controls

\begin{tabular}{|c|c|c|c|c|c|c|}
\hline Regions & Hemisphere & $\begin{array}{l}\text { Cluster size } \\
\text { (voxels) }\end{array}$ & $\begin{array}{l}\text { Number of voxels } \\
\text { within the anatomical region }\end{array}$ & $P$-value (FWE cluster-level) & Peak t values & MNI coordinates $(x, y, z)$ \\
\hline \multicolumn{7}{|l|}{$\mathrm{BN}<\mathrm{HC}$} \\
\hline Cluster 1 & & 1704 & & $<0.001$ & -5.73 & $-1.5,52.5,7.5$ \\
\hline Frontal_Sup_Medial_L & Left & & 855 & & & \\
\hline Cluster 2 & & 767 & & $<0.001$ & -4.57 & $52.5,-33,18$ \\
\hline Temporal_Sup_R & Right & & 347 & & & \\
\hline Cluster 3 & & 876 & & $<0.001$ & -4.85 & $-1.5,1.5,42$ \\
\hline Cingulum_Mid_R & Right & & 364 & & & \\
\hline Cluster 4 & & 1042 & & & & \\
\hline Cingulum_Mid_L & Left & & 512 & $<0.001$ & -4.42 & $-6,-42,46.5$ \\
\hline Cluster 5 & & 705 & & & & \\
\hline Frontal_Sup_L & Left & & 366 & $<0.001$ & -4.69 & $-24,18,55.5$ \\
\hline
\end{tabular}




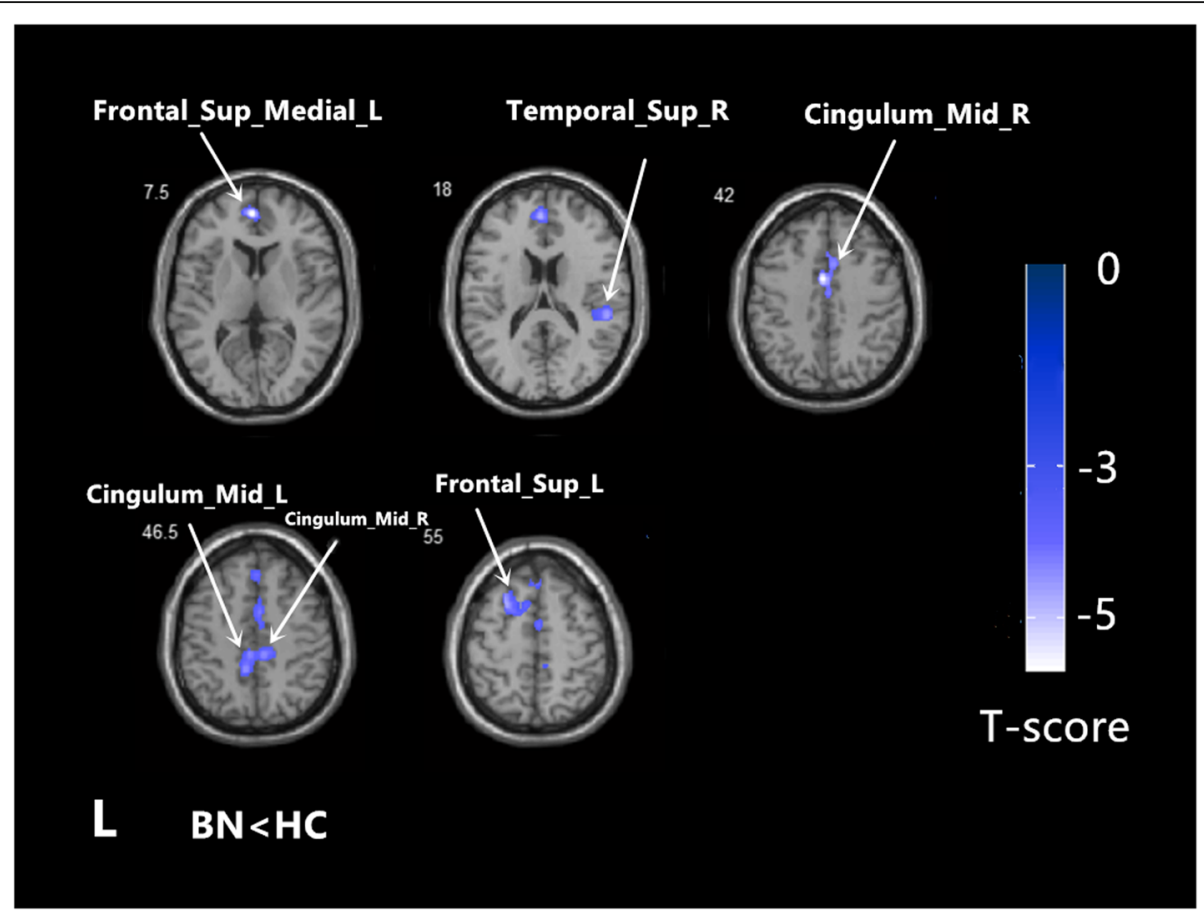

Fig. 1 Regional grey matter volume alterations in BN $(n=34)$ relative to $\mathrm{HC}(n=40)$. The statistical brain maps showed regional GMV decrease in $B N$, including the SFGmed. L, the STG. R, DCG. L, DCG. R and SFGdor. L $(P<0.001$, corrected at cluster level). The color bar represents the t-scores

of German patients [20] but not with a second German group [18]. These differences may reflect differences in methodology. Our observation of increased CSF volume but unchanged TIV suggests that the reduced GMV in BN is replaced by increased CSF.

\section{Regional GMV alterations}

Patients showed reduced GMV in the SFGmed. L, STG. R, DCG. L, DCG. R and SFGdor. L, and no regions with increased GMV. These results are consistent with some studies but not with others, which have reported reduced GMV in the superior frontal gyrus and cingulate cortices [6], increased GMV in the medial orbital frontal cortex and the ventral striatum [4], or increased GMV in the paracentral lobule, precuneus, left putamen and insula, but reduced GMV in the caudate nucleus and thalamus [19]. Thus, different studies of BN patients vary considerably in the regions showing GMV alterations and the direction of the alteration (increase or decrease). These discrepancies may be due to differences in disease course, disease stage, medication history, ethnicity and other factors. Future studies should strive to examine larger, multi-center populations that may help reduce the influence of clinico-demographic factors on VBM.

The SFG is located in the superior part of the prefrontal cortex, which plays essential roles in executive control [21], including self-regulation of eating behavior [22]. The structural and functional abnormalities in the
SFG in patients with $\mathrm{BN}$ or other eating disorders have been associated with deficits in self-regulation and reward processing [23]. Functional MRI studies have shown the SFG to be deactivated in BN in the presence of the expected reward during a reward-based learning task [24], during a Simon spatial incompatibility task [23]. The prefontal cortex is an important part of the fronto-striatal circuits, which is involved in selfregulatory control. Previous study has found deficient activity in the fronto-striatal circuits associated with impaired self-regulatory processes $[23,25]$. The prefrontal cortex is also an important component of the forebrain system, which may contribute to eating dysregulation by driving maladaptive over- and undereating [26]. These alterations are likely lead to binge eating behaviors, thereby contributing to the development and maintenance of $\mathrm{BN}$.

Reduced STG volume may cause abnormal body image perception and excessive concern about body shape and weight, leading to restrictive or binge eating. The GMV reduction in the STG in the Japanese study was associated with body dissatisfaction [27]. A functional MRI study has shown deactivation in STG when the individual was thinking about eating food [28]. Patients with eating disorders such as BN typically show emotional symptoms such as depressive and anxiety disorders $[14,29]$. How these symptoms relate to inappropriate eating behaviors is controversial. Many studies 


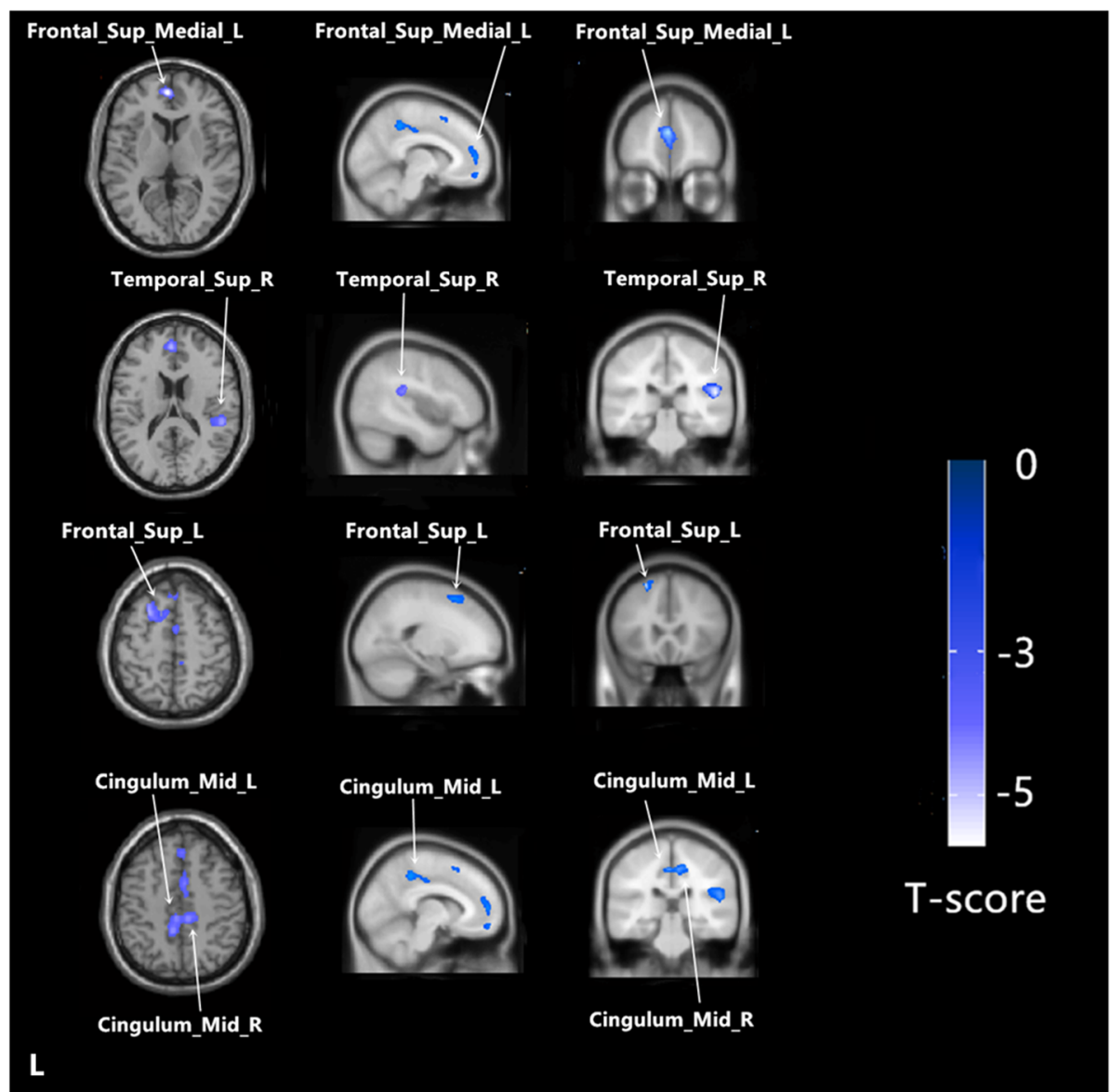

Fig. 2 The sagittal/transvere/coronal views for each cluster $(P<0.001$, corrected at cluster level). The color bar represents the t-scores

have suggested that inappropriate eating behaviors are maladaptive strategies to manage negative feelings [30]. However, other studies have suggested that the eating behaviors alter mental state, such as by activating serotonin projections of the dorsal raphe to the prefrontal cortex; as a result, normalizing eating behavior can normalize psychiatric symptoms [31]. We found reduced GMV volume in the STG of our BN patients, which may link to more severe symptoms of depression and anxiety disorders [32, 33]. Such a reduction has also been linked to risk of suicide attempts in community samples of adolescents [34]. Further studies should examine whether such GMV reductions precede or follow the onset of inappropriate eating behaviors.

We observed reduced GMV in the middle cingulate cortex, and such a reduction has been rarely reported in $\mathrm{BN}$. The middle cingulate cortex is associated with inhibitory functions and self-control, GMV in the middle cingulate cortex negtively correlated with uncontrlled eating behaviors has been reported in normal-weight female undergraduate students [35]. In addition, obese individuals in one study showed reduced activation of the middle cingulate cortex during appetite control [36]. The structural and functional alterations of the middle cingulate cortex in $\mathrm{BN}$ patients should be explored further.

\section{Correlations between GMV alterations and clinical variables}

$\mathrm{BN}$-associated GMV reductions did not vary significantly with BMI, duration of illness, or total scores on the RSES or CSES. Age did, however, correlate negatively with GMV in the SFGmed. L, DCG. R, DCG. L and SFGdor.L.

As expected, RSES and CSES scores were lower in BN patients than in controls, reflecting that a frequent symptom of BN is body image dissatisfaction [37], which is linked to low self-esteem $[38,39]$. At the beginning of this study, we hypothesized that the RSES and CSES scores of BN patients would be associated with GMV alterations. However, we did not observe such an association in our patients. In contrast, a study of BN patients in the US did detect an association between brain functional alterations and self-esteem: activation of the right 


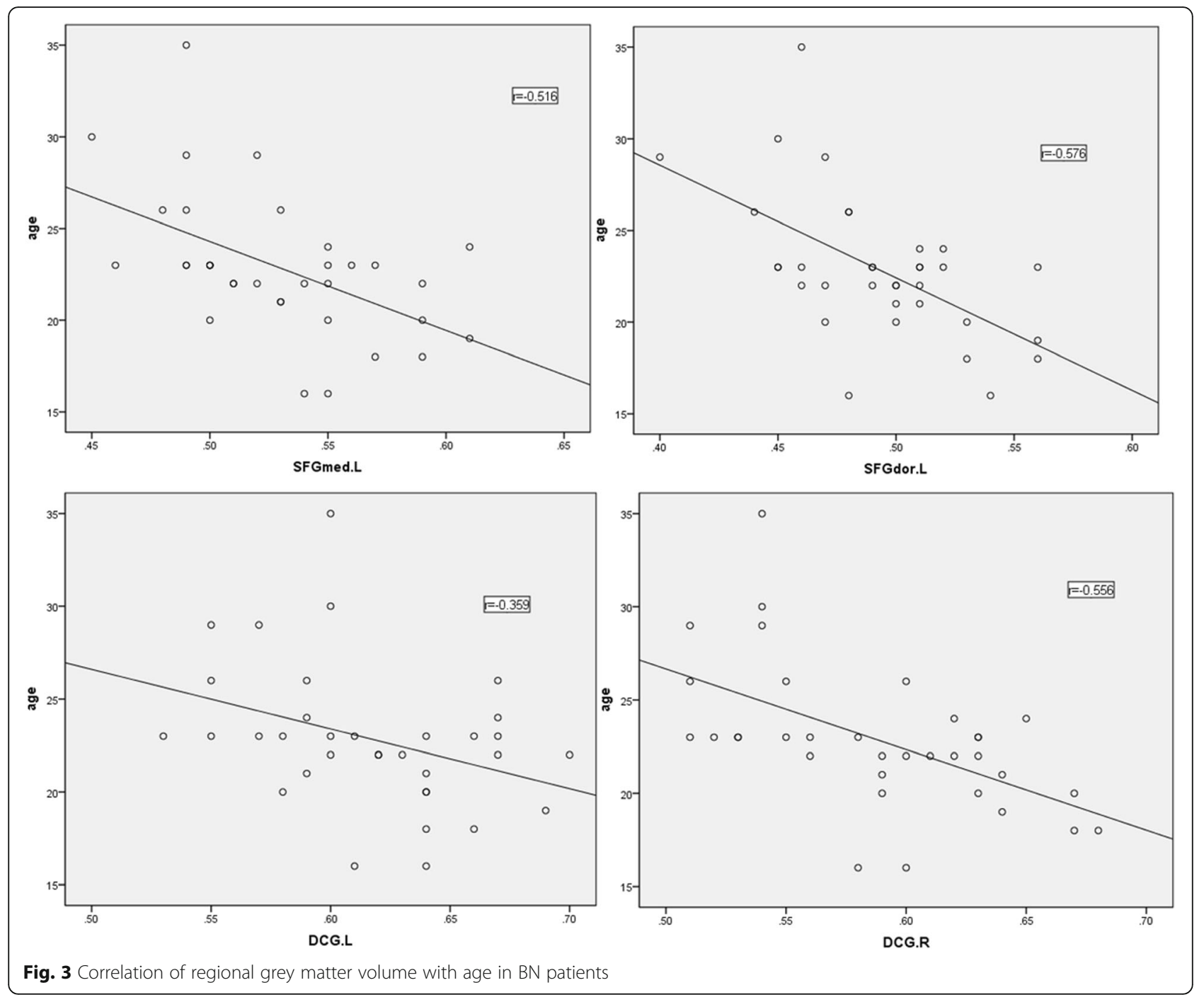

temporoparietal junction, precuneus and dorsal anterior cingulate cortex was weaker in BN patients than in controls during execution of social and self-knowledge tasks [40]. These brain regions are associated with selfknowledge and social processing. The discrepancy between that study and ours may be due to methodological differences. Whether the GMV reductions in our BN patients correlate with functional changes affecting selfesteem and self-evaluation should be explored further.

\section{Study limitations}

This study analyzed only women, even though some men are also affected by eating disorders. In addition, some of our patients had mild anxiety and depressive symptoms, which may have confounded our results but which may also make our sample more representative of typical BN patient populations [14]. The cross-sectional nature of our study means that further work is needed to clarify whether the observed GMV alterations are the result of $\mathrm{BN}$ pathology or the consequence of binge-eating and compensatory behaviors. Our results should be verified and extended with much larger samples. In our study, we explored only brain structural alterations in $\mathrm{BN}$; future work should explore changes in brain functional connectivity and networks in order to understand how brain areas interact with one another.

\section{Conclusions}

The present study showed regional GMV decreases in several brain areas of women with BN. These structural alterations may be associated with impaired inhibitory control, body dissatisfaction, and emotion dysrugulation. While these GMV reductions correlated with patient age, they did not correlate with self-esteem or selfevaluation. These findings should be verified and extended in larger, preferably longitudinal studies. 


\section{Abbreviations}

AN: Anorexia nervosa; BMI: Body mass index; BN: Bulimia nervosa; CSES: Core Self-Evaluation Scale; CSF: Cerebrospinal fluid; DCG.L: Left median cingulate and paracingulate gyri; DCG.R: Right median cingulate and paracingulate gyri; GM: grey matter; GMV: Grey matter volume; MRI: Magnetic resonance imaging; ROI: Region of interest; RSES: Rosenberg Self-Esteem Scale; SCID: Structured clinical interview for DSM-V disorders; SFGdor.L: Left dorsolateral superior frontal gyrus; SFGmed.L: Left medial superior frontal gyrus; SPSS: Statistical Package for the Social Sciences; STG.R: Right superior temporal gyrus; TE: Echo time; TIV: Total intracranial volume; TR: Repetition time; VBM: Voxel-based morphometry; WM: White matter; WMV: White matter volume

\section{Acknowledgments}

The authors would like to thank all subjects for contributing their time and efforts to this study.

\section{Authors' contributions}

LZ, YW and $X L$ designed the study. LLZ, LFL, YYL and JM recruited patients and collected demographic data. XL, XWL and YW collected MRI data. XL and $X W L$ analyzed and interpreted the results. $X L$ drafted the manuscript which $L Z$ revised. All authors read and approved the final manuscript.

\section{Authors' information}

XL, LFL, LLZ and JM are master's candidates at the Mental Health Center, West China Hospital of Sichuan University. XXL is a psychiatry resident and YW a PhD candidate at the Mental Health Center. YYL is a psychiatry resident at Zunyi Psychiatric Hospital in Guizhou province.

\section{Funding}

This study was supported by funds for postgraduate training from Sichuan University.

\section{Availability of data and materials}

The datasets analyzed during the current study are available from the corresponding author on reasonable request.

\section{Ethics approval and consent to participate}

The study was approved by the Ethics Committee of West China Hospital of Sichuan University. All participants provided written informed consent.

\section{Consent for publication}

Not applicable

\section{Competing interests}

The authors declare that they have no competing interests.

\section{Author details}

'Mental Health Center, West China Hospital, Sichuan University, No. 28 Dian Xin Nan Road, Chengdu 610041, Sichuan, China. 'Zun Yi Psychiatric Hospital, Zunyi 563000, Guizhou, China.

\section{Received: 7 November 2019 Accepted: 11 February 2020}

19.

\section{References}

1. American Psychiatric Association. Diagnostic and statistical manual of mental disorder. Arlington VA: American Psychiatric Publishing; 2013. p. 5.

2. Gibson D, Workman C, Mehler PS. Medical complications of anorexia nervosa and bulimia nervosa. Psychiat Clin N Am. 2019;42(2):263-74.

3. Sachs K, Mehler PS. Medical complications of bulimia nervosa and their treatments. Eat Weight Disord. 2016;21(1):13-8.

4. Schäfer A, Vaitl D, Schienle A. Regional grey matter volume abnormalities in bulimia nervosa and binge-eating disorder. NEUROIMAGE. 2010;50(2): 639-43.

5. Frank GK, Shott ME, Hagman JO, Mittal VA. Alterations in brain structures related to taste reward circuitry in ill and recovered anorexia nervosa and in bulimia nervosa. Am J Psychiat. 2013;170(10):1152-60.

6. Marsh R, Stefan M, Bansal R, Hao X, Walsh BT, Peterson BS. Anatomical characteristics of the cerebral surface in bulimia nervosa. Biol Psychiat. 2015; 77(7):616-23.
7. Coutinho J, Ramos AF, Maia L, Castro L, Conceição E, Geliebter A, Machado PPP, Gonçalves Ó, Sampaio A. Volumetric alterations in the nucleus accumbens and caudate nucleus in bulimia nervosa: a structural magnetic resonance imaging study. Int J Eat Disorder. 2015:48(2):206-14.

8. Westwater ML, Seidlitz J, Diederen KMJ, Fischer S, Thompson JC. Associations between cortical thickness, structural connectivity and severity of dimensional bulimia nervosa symptomatology. Psychiatry Res Neuroimaging. 2018;271:118-25.

9. Berner LA, Stefan M, Lee S, Wang Z, Terranova K, Attia E, Marsh R. Altered cortical thickness and attentional deficits in adolescent girls and women with bulimia nervosa. J Psychiatr Neurosci. 2018;43(3):151-60.

10. Frank GKW, Shott ME, Riederer J, Pryor TL. Altered structural and effective connectivity in anorexia and bulimia nervosa in circuits that regulate energy and reward homeostasis. Transl Psychiat. 2016;6(11):e932.

11. Boucher K, Côté M, Gagnon-Girouard MP, Bégin C. Eating pathology among patients with anorexia nervosa and bulimia nervosa: the role of narcissism and self-esteem. J Nerv Ment Dis. 2018:206:776-82.

12. Blechert J, Ansorge U, Beckmann S, Tuschen-Caffier B. The undue influence of shape and weight on self-evaluation in anorexia nervosa, bulimia nervosa and restrained eaters: a combined ERP and behavioral study. Psychol Med. 2011;41(1):185-94.

13. Hudson Jl, Hiripi E, Pope HG, Kessler RC. The prevalence and correlates of eating disorders in the National Comorbidity Survey Replication. Biol Psychiat. 2007;61(3):348-58.

14. Godart N, Radon L, Curt F, Duclos J, Perdereau F, Lang F, Venisse JL, Halfon O, Bizouard P, Loas G, et al. Mood disorders in eating disorder patients: prevalence and chronology of ONSET. J Affect Disorders. 2015; 185:115-22

15. DuJianzheng ZZ. Reliability, validation and construct confirmatory of core self-evaluation. Psychol Res. 2012;03:54-60.

16. Rosenberg. Society and the adolescent self-image. United States of America: Princeton University Press; 1965.

17. Hong L. Research on the self-esteem of college students. Studies Psychol Behav. 2003:02:133-6.

18. Joos A, Klöppel S, Hartmann A, Glauche V, Tüscher O, Perlov E, Saum B, Freyer T, Zeeck $A$, van Elst LT. Voxel-based morphometry in eating disorders: correlation of psychopathology with grey matter volume. Psychiatry Res Neuroimaging. 2010;182(2):146-51.

19. Amianto F, Caroppo P, D Agata F, Spalatro A, Lavagnino L, Caglio M, Righi $D$, Bergui M, Abbate-Daga $G$, Rigardetto $R$, et al. Brain volumetric abnormalities in patients with anorexia and bulimia nervosa: a voxel-based morphometry study. Psychiatry Res Neuroimaging. 2013;213(3):210-6.

20. Krieg JC, Lauer C, Pirke KM. Structural brain abnormalities in patients with bulimia nervosa. Psychiatry Res. 1989;27(1):39-48.

21. Funahashi S, Andreau JM. Prefrontal cortex and neural mechanisms of executive function. J Physiol Paris. 2013;107(6):471-82.

22. Dohle $S$, Diel K, Hofmann W. Executive functions and the self-regulation of eating behavior: a review. Appetite. 2018;124:4-9.

23. Marsh R, Horga G, Wang Z, Wang P, Klahr KW, Berner LA, Walsh BT, Peterson BS. An FMRI study of self-regulatory control and conflict resolution in adolescents with bulimia nervosa. Am J Psychiatry. 2011;168(11):1210-20.

24. Cyr M, Wang Z, Tau GZ, Zhao G, Friedl E, Stefan M, Terranova K, Marsh R. Reward-Based Spatial Learning in Teens With Bulimia Nervosa. J Am Acad Child Psy. 2016;55(11):962-71.

25. Marsh R, Steinglass JE, Gerber AJ, Graziano O, Leary K, Wang Z, Murphy D, Walsh BT, Peterson BS. Deficient activity in the neural systems that mediate self-regulatory control in bulimia nervosa. Arch Gen Psychiatry. 2009;66(1): 51-63.

26. Petrovich GD. Forebrain networks and the control of feeding by environmental learned cues. Physiol Behav. 2013;121:10-8.

27. Kohmura K, Adachi Y, Tanaka S, Katayama H, Imaeda M, Kawano N, Nishioka $\mathrm{K}$, Ando $\mathrm{M}$, lidaka T, Ozaki N. Regional decrease in gray matter volume is related to body dissatisfaction in anorexia nervosa. Psychiatry Res Neuroimaging. 2017:267:51-8.

28. Brooks SJ, O'Daly OG, Uher R, Friederich HC, Giampietro V, Brammer M, Williams SC, Schiöth HB, Treasure J, Campbell IC. Differential neural responses to food images in women with bulimia versus anorexia nervosa. PLoS One. 2011:6(7):e22259.

29. Kaye WH, Bulik CM, Thornton L, Barbarich N, Masters K, The PFCG Comorbidity of anxiety disorders with anorexia and bulimia nervosa. Am J Psychiat. 2004;161(12):2215-21. 
30. Lavender JM, Wonderlich SA, Peterson CB, Crosby RD, Engel SG, Mitchell JE, Crow SJ, Smith TL, Klein MH, Goldschmidt AB, et al. Dimensions of emotion dysregulation in bulimia nervosa. Eur Eat Disord Rev. 2014;22(3):212-6.

31. loakimidis I, Zandian M, Ulbl F, Bergh C, Leon M, Södersten P. How eating affects mood. Physiol Behav. 2011;103(3-4):290-4.

32. van Tol MJ, van der Wee NJ, van den Heuvel OA, Nielen MM, Demenescu $L R$, Aleman A, Renken R, van Buchem MA, Zitman FG, Veltman DJ. Regional brain volume in depression and anxiety disorders. Arch Gen Psychiatry. 2010;67(10):1002-11.

33. Lai $C$, Wu $Y$. The gray matter alterations in major depressive disorder and panic disorder: putative differences in the pathogenesis. J Affect Disorders. 2015;186:1-6.

34. Pan LA, Ramos L, Segreti A, Brent DA, Phillips ML. Right superior temporal gyrus volume in adolescents with a history of suicide attempt. Brit J Psychiat. 2015:206(4):339-40.

35. Song S, Zhang Y, Qiu J, Chen $\mathrm{H}$, et al. Brain structures associated with eating behaviors in normal-weight young females. Neuropsychologia. 2019; 133:107171.

36. Tuulari JJ, Karlsson HK, Hirvonen J, et al. Neural circuits for cognitive appetite control in healthy and obese individuals: an fMRI study. PLoS One. 2015;10(2):e0116640

37. Bowden PK, Touyz SW, Rodriguez PJ, Hensley R, Beumont PJ. Distorting patient or distorting instrument? Body shape disturbance in patients with anorexia nervosa and bulimia. Br J Psychiatry. 1989;155(2):196-201.

38. Meijboom A, Jansen A, Kampman M, Schouten E. An experimental test of the relationship between self-esteem and concern about body shape and weight in restrained eaters. Int J Eat Disord. 1999;25(3):327-34.

39. Laporta-Herrero I, Jáuregui-Lobera I, Barajas-Iglesias B, Santed-Germán MÁ. Body dissatisfaction in adolescents with eating disorders. Eat Weight Disord. 2018;23(3):339-47.

40. McAdams CJ, Krawczyk DC. Neural responses during social and selfknowledge tasks in bulimia nervosa. Front Psychiatry. 2013;4.

\section{Publisher's Note}

Springer Nature remains neutral with regard to jurisdictional claims in published maps and institutional affiliations.

Ready to submit your research? Choose BMC and benefit from:

- fast, convenient online submission

- thorough peer review by experienced researchers in your field

- rapid publication on acceptance

- support for research data, including large and complex data types

- gold Open Access which fosters wider collaboration and increased citations

- maximum visibility for your research: over $100 \mathrm{M}$ website views per year

At $\mathrm{BMC}$, research is always in progress.

Learn more biomedcentral.com/submissions 